\title{
Colposcopy in a family planning clinic: A future model?
}

\author{
H C KITCHENER, R A BURNETT, E S B WILSON, J W CORDINER
}

\begin{abstract}
The first year's experience of a satellite colposcopy clinic in the Glasgow Family Planning Centre was analysed. Establishment of the clinic was supervised by an experienced member of the colposcopy team at the department of gynaecology, Western Infirmary, Glasgow, who trained one of the family planning centre's staff. Close links were thus maintained with the hospital clinic to which patients were referred for treatment. The policy at the new colposcopy clinic was to study prospectively all women in the hospital catchment area whose cervical smears were reported as abnormal. In 58 of 162 such patients there was at least moderate dyskaryosis and the cytologist's recommendation had been referral for colposcopy. In 104 cases the changes were either atypia alone or mild dyskaryosis and a repeat smear was recommended within three to 12 months; 18 of these patients had grade II or III cervical intraepithelial neoplasia on biopsy, and relying on repeat smears would have resulted in an $11.7 \%$ false negative rate.

If an atypical cytological picture is to be an indication for colposcopy clinics attached to family planning centres may have an important role, given satisfactory training and close links with central specialist colposcopy clinics.
\end{abstract}

\section{Introduction}

With the dramatic rise in preinvasive disease of the cervix in young women in recent years there has been a need to increase greatly the provision of colposcopy in the United Kingdom. This has resulted

Glasgow University Department of Midwifery, The Queen Mother's Hospital, Glasgow G3 8SH

H C KITCHENER, MD, MRCOG, senior registrar

J W CORDINER, FRCS, FRCOG, consultant

Department of Pathology, Western Infirmary, Glasgow

R A BURNETT, MRCPATH, consultant

Family Planning Services, Greater Glasgow Health Board

E S B WILSON, MB, BS, area coordinator.

Correspondence to: Dr Kitchener. in many more colposcopists, ever increasing numbers of patients at their clinics, and difficulty in preventing lengthening waiting times.

The impression that cytology frequently underestimates the degree of cervical abnormality has been the subject of two recent reports from Gateshead ${ }^{1}$ and Dundee. ${ }^{2}$ These studies suggest that ideally colposcopy should be available to many women whose smears hitherto were reported as showing atypical features calling for a repeat smear. Such a policy would substantially increase the burden on colposcopy services, which in many places are already overstretched.

In order to provide quicker access to colposcopy for patients attending the family planning centre and at the same time reduce the number of patients referred for diagnostic colposcopy at the Western Infirmary a colposcopy clinic was set up at the Glasgow Family Planning Centre. This is a large clinic which formerly referred patients with abnormal smears for colposcopy at the Western Infirmary.

The initial policy was to offer colposcopy to all women whose smears indicated the need either for colposcopy or for a repeat smear. In this way it was hoped to evaluate prospectively the failure to detect cervical intraepithelial neoplasia on repeat smears and the additional workload if colposcopy were to replace repeated cytology.

\section{Methods and patients}

The trainee colposcopist initially attended the colposcopy clinic at the Western Infirmary for several teaching sessions using video equipment as well as the colposcope. The new clinic, which began in January 1986, was run by HCK and training was on a one to one basis. Equipment was installed at a cost of $£ 5000$, provided from charitable funds. Smears and punch biopsy samples were examined in the pathology department at the hospital. Correspondence and administration were handled in the family planning centre, but patients requiring either laser treatment or cone biopsy received this at the Western Infirmary. The new colposcopy clinic developed its own separate case sheet with a standard form.

The clinic was held fortnightly, and initially only six new patients were allocated to each clinic in order to allow time for teaching. We anticipated that as patients returned for follow up total numbers would at least double, and this proved to be the case by the end of one year. Cytological and histological reports were always reviewed with the colposcopy forms by both the trainee and the supervisor. After six months the trainee ran a few clinics without problems and during the second half of the year attended a basic colposcopy course, which is designed to complement practical knowledge 
already gained. We now consider that the trainee is competent in basic colposcopy.

All patients at the family planning centre but domiciled in the hospital's catchment area whose smears showed any degree of abnormality were offered colposcopy. In the first year 162 women were examined. Our cytology laboratory reports smears as "normal," "suspicious," or "positive." After a repeat smear colposcopy was performed in standard fashion. Acetic acid $5 \%$ was applied to the cervix and one or more directed punch biopsy specimens taken by using Leech-Wilkinson forceps. After treatment for cervical intraepithelial neoplasia patients were reviewed at four and 12 months by cytology and colposcopy to exclude residual and recurrent disease.

\section{Results}

During the first 12 months 162 women had colposcopy because of an abnormal smear. Seven women with a clinically suspicious cervix and normal smears were excluded from the study; all were normal on colposcopy.

Of the 162 women studied, $58(36 \%)$ had smears reported as suspicious with a recommendation for colposcopy, $55(34 \%)$ had smears showing only mild dyskaryosis for which a repeat smear was recommended, and the remaining 49 (30\%) had smears with no dyskaryosis but atypical features with inflammatory or viral change for which the cytologist had also recommended a repeat smear. Table I shows the results of the smear repeated at the time of colposcopy. Of the 49 women with initial atypical smears, $31(63 \%)$ had normal repeat smears and only one showed even mild

TABLE I-Correlation of initial and repeat smears done at time of colposcopy $(n=162)$

\begin{tabular}{lccc}
\hline & \multicolumn{3}{c}{ First smear } \\
\cline { 2 - 4 } Repeat smear & Atypical & Mildly dyskaryotic & Suspicious \\
\hline Normal & $31(3)^{\star}$ & $29(4)^{\star}$ & 14 \\
Atypical & 15 & 3 & 4 \\
Mildly dyskaryotic & 1 & 7 & 7 \\
Suspicious & 0 & 14 & 31 \\
Not repeated & 2 & 2 & 2 \\
\hline Total & 49 & 55 & 58
\end{tabular}

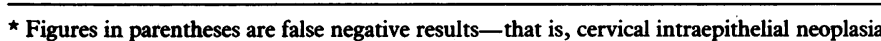
found on biopsy.

TABLE II-Histological findings in relation to initial smears $(n=162)$

\begin{tabular}{lccc}
\hline & \multicolumn{3}{c}{ First smear } \\
\cline { 2 - 4 } Histology & Atypical & $\begin{array}{c}\text { Mildly } \\
\text { dyskaryotic }\end{array}$ & Suspicious \\
\hline Not done & 0 & 19 & 8 \\
Normal & 27 & 10 & 10 \\
Viral & 15 & 12 & 8 \\
Cervical intraepithelial neoplasia stage I & $2(1)^{\star}$ & $1 \dagger$ & 1 \\
Cervical intraepithelial neoplasia stage II & $4(1)^{\star}$ & $5(2)^{\star}$ & 15 \\
Cervical intraepithelial neoplasia stage III & $1(1)^{\star}$ & $8(2)^{\star} \ddagger$ & 15 \\
Invasive & 0 & 0 & 1 (adenocarcinoma) \\
\hline \multicolumn{1}{c}{ Total } & 49 & 55 & 58 \\
\hline
\end{tabular}

* Figures in parentheses are women with normal repeat smears.

† Glandular intraepithelial neoplasia.

$\neq$ One of these showed adenocarcinoma in situ. dyskaryosis. Of the 55 with mildly dyskaryotic smears initially, in only seven (13\%) was the repeat smear similarly reported; in 29 cases (53\%) these were reported as normal and in 14 cases $(25 \%)$ as suspicious. Of 58 women with suspicious smears initially, only $14(24 \%)$ had normal repeat smears. When the original 104 atypical and mildly dyskaryotic smears are taken together 60 $(58 \%)$ of the repeat smears were normal; in seven $(11.7 \%)$ of these, however, cervical intraepithelial neoplasia grade II or III was found on punch biopsy

Table II summarises the histological results. Of the women with atypical features only on the initial smear, 22 (45\%) showed koilocytosis on biopsy, and one third of these also had evidence of cervical intraepithelial neoplasia. The 55 women with initially mildly dyskaryotic smears included $14(25 \%)$ with cervical intraepithelial neoplasia, which in eight cases (14\%) was grade III; there were two cases of glandular dysplasia in this group, one showing mild changes and the other amounting to adenocarcinoma in situ; 12 patients in this group had koilocytosis alone on biopsy. In the group with suspicious smears initially in whom colposcopy had been recommended 18 women (31\%) had no obvious histological abnormality, eight (14\%) had viral lesions, and there were $15(26 \%)$ examples each of cervical intraepithelial neoplasia grade II and cervical intraepithelial neoplasia grade III. One patient had a colposcopically directed biopsy which showed cervical intraepithelial neoplasia grade III and koilocytosis, but because the squamocolumnar junction was not seen a bone biopsy was performed and this showed an early adenocarcinoma of the cervix.

Table III shows the correlation of histological and cytological findings at the time of colposcopy. Conditions are optimal in a colposcopy clinic for good cytological preparations, so that close correlation might be expected. Twenty two $(30 \%)$ of the normal repeat smears were associated with an abnormal biopsy specimen and in $12(27 \%)$ of the suspicious smears there was no dysplasia compared with half of the initial smears which were not associated with cervical intraepithelial neoplasia.

Fifty three patients $(33 \%)$ had treatment. In 38 this was by laser and 14 had cone biopsy. The patient with adenocarcinoma had a radical hysterectomy, which showed no spread to lymph nodes. In the patient with adenocarcinoma in situ cone biopsy suggested incomplete excision, though at subsequent hysterectomy there was no residual disease.

\section{Discussion}

Because of the considerable flexibility required there are no official guidelines set down by the British Society for Colposcopy and Cervical Pathology for training in colposcopy. The programme of training that we used offered one to one training by. an experienced colposcopist with adequate numbers of patients representing a full range of cervical disorders as well as many normal cases. Two particularly important aspects are the selection of patients for cone biopsy and the decision to discharge a woman to cytological follow up. The theoretical basic colposcopy course, coming after several months of initial teaching, complemented the practical experience but can never replace adequate practical training.

In establishing a colposcopy service at the family planning centre we hoped to provide more rapid access to colposcopy, with the service being available in familiar clinic surroundings. This avoided the waiting time for colposcopy at the Western Infirmary, which is six weeks and increasing. The number of referrals to the Western Infirmary for colposcopy as an initial procedure more than doubled in two years, from 269 in 1984 to 569 in 1986, excluding the patients in this study. This dramatic increase has not been met by extra secretarial, nursing, or medical staff.

The colposcopy clinic at the family planning centre afforded the

TABLE III-Hiștological findings compared with cytological results at time of colposcopy $(n=162)$

\begin{tabular}{|c|c|c|c|c|c|c|}
\hline \multirow[b]{2}{*}{ Histology } & \multirow[b]{2}{*}{ Not done } & & \multicolumn{2}{|c|}{ Smear } & & \multirow[b]{2}{*}{ Total (\%) } \\
\hline & & Normal & Atypical & Mildly dyskaryotic & Suspicious & \\
\hline $\begin{array}{l}\text { Not done } \\
\text { Normal } \\
\text { Viral } \\
\text { Cervical intraepithelial neoplasia stage I } \\
\text { Cervical intraepithelial neoplasia stage II } \\
\text { Cervical intraepithelial neoplasia stage III } \\
\text { Invasive }\end{array}$ & $\begin{array}{l}0 \\
2 \\
0 \\
0 \\
2 \\
2 \\
0\end{array}$ & $\begin{array}{r}20 \\
32 \\
14 \\
1 \\
3 \\
4 \\
0\end{array}$ & $\begin{array}{l}3 \\
6 \\
9 \\
1 \\
3 \\
0 \\
0\end{array}$ & $\begin{array}{l}5 \\
3 \\
3 \\
1 \\
2 \\
1 \\
0\end{array}$ & $\begin{array}{r}0 \\
4 \\
8 \\
1 \\
14 \\
17 \\
1\end{array}$ & $\begin{array}{c}28(17 \cdot 3) \\
47(29 \cdot 0) \\
34(21 \cdot 0) \\
4(2 \cdot 5) \\
24(14 \cdot 8) \\
24(14 \cdot 8) \\
1(0 \cdot 6)\end{array}$ \\
\hline Total (\%) & $6(3 \cdot 7)$ & $74(45 \cdot 7)$ & $22(13 \cdot 6)$ & $15(9 \cdot 3)$ & $45(27 \cdot 7)$ & \\
\hline
\end{tabular}


opportunity to investigate the prevalence of cervical intraepithelial neoplasia in women with atypical and mildly dyskaryotic smears. The recent retrospective reports on this subject ${ }^{12}$ may not reflect the current situation accurately because of the accelerating prevalence of wart virus infection in the past three or four years. The prospective nature of the study avoided problems of selection, apart from the age range being limited to that relevant to a family planning clinic.

The different terminology and grading systems used for cytological assessment in various parts of the United Kingdom make it difficult to compare published results. Uniformity of nomenclature is required. ${ }^{3}$

Our study disclosed a $25 \%$ incidence of grade II or III cervical intraepithelial neoplasia in women with mildly dyskaryotic smears, indicating that referral to colposcopy and not a repeat smear is the proper recommendation; indeed, a subsequent normal smear would have been falsely reassuring in $31 \%$ (4/13) of these cases. Even the non-dyskaryotic atypical smears produced a $10 \%$ incidence of cervical intraepithelial neoplasia grade II or III, and though referral for colposcopy for all these women would be the ideal, it is probably not feasible given current resources. The figures from Gateshead and Dundee ${ }^{2}$ are even more worrying, with an incidence of $49 \%$ and $69 \%$ respectively for mildly dyskaryotic smears, compared with $37 \%$ and $29 \%$ for atypical smears. There may have been selection for a degree of greater cytological abnormality in these retrospective studies because the patients were actually referred for colposcopy. Though colposcopy cannot be regarded as a screening procedure, clearly cytology does not predict with great specificity or sensitivity the need for colposcopy. Increasing the number of colposcopy clinics appears to be necessary. Some might argue that this should be restricted within specialist gynaecological practice, but we think that provided that there are close working links with the hospital centre large referring clinics can establish a successful colposcopy service.

Apart from providing more rapid access to colposcopy for patients who have abnormal smears many patients favour having the procedure at their own clinic as opposed to hospital. We plan to link the family planning centre colposcopy clinic by computer in order to be able to access all the relevant information to the computer in the Western Infirmary. Our experience leads us to agree with Soutter $e t$ $a l^{\prime}$ that any degree of dyskaryosis merits colposcopy. Furthermore, a non-dyskaryotic, atypical smear requires either colposcopy or two follow up smears within one year if false negative results are to be minimised; these occurred in seven of the 60 cases $(11.7 \%)$ with a single repeat smear in our series. This policy will result in increased referral for diagnostic colposcopy, and the establishment of this kind of clinic may help absorb the extra workload.

This work was supported in part by Birthright. Professor C R Whitfield read the manuscript and provided valuable criticism.

\section{References}

1 Soutter WP, Wisdom S, Brough A, Monaghan JM. Should patients with mild atypia in a cervical smear be referred for colposcopy? Brf Obstet Gynaecol 1986;93:70-4.

2 Walker EM, Dodgson J, Duncan ID. Does mild atypia warrant further investigation? Lancet 1986;ii:672-3.

3 Evans DMB, Hudson EA, Brown CL, et al. Terminology in gynaecological cytology: report of the Working Party of the British Societies for Clinical Cytology. J Clin Pathol 1986;39:933-44. (Accepted 9 April 1987)

\title{
Cigar and pipe smoking and myocardial infarction in young men
}

\author{
DAVID W KAUFMAN, JULIE R PALMER, LYNN ROSENBERG, SAMUEL SHAPIRO
}

\begin{abstract}
The effect of cigar and pipe smoking on the risk of myocardial infarction was evaluated in an interview study of $\mathbf{5 7 2}$ men with non-fatal first myocardial infarctions and $\mathbf{9 3 4}$ hospital controls. The study was conducted in the north eastern United States from 1980 to 1983. All subjects were 40-54 years of age, and none had smoked cigarettes for at least two years. Among men who had never smoked cigarettes the relative risk of myocardial infarction for those who smoked at least five cigars a day, compared with not smoking cigars and pipes and allowing for other risk factors, was estimated to be 1.7 ( $95 \%$ confidence interval 0.6 to 4.8 ). Among ex-smokers of cigarettes the corresponding estimate for those who smoked at least five cigars a day was $4 \cdot 5(2 \cdot 2$ to $9 \cdot 2)$.
\end{abstract}

Slone Epidemiology Unit, School of Public Health, Boston University School of Medicine, Brookline, Massachusetts, USA

DAVID W KAUFMAN, sCD, assistant research professor

JULIE R PALMER, MPH, epidemiologist

LYNN ROSENBERG, SCD, associate research professor

SAMUEL SHAPIRO, MB, FRCPED, research professor

Correspondence and requests for reprints to: Dr David W Kaufman, Slone Epidemiology Unit, Boston University School of Medicine, Brookline, MA 02146, USA.
The estimates for men who smoked fewer cigars, or pipes, were closer to 1.0 and not significant.

Men who stop smoking cigarettes and switch to at least five cigars a day apparently continue to have an increased risk of myocardial infarction, possibly because they continue to inhale the smoke.

\section{Introduction}

Many cigarette smokers switch to cigars or pipes in an effort to reduce the risk to their health. We have little information on how this affects their risk of coronary heart disease, ${ }^{1}$ but it is thought that the risk is somewhat higher than for non-smokers and considerably lower than for cigarette smokers. ${ }^{2}$ We evaluated the risk of non-fatal myocardial infarction in relation to cigar and pipe smoking in a large case-control study of men under 55 .

\section{Subjects and methods}

The study was conducted in the north eastern United States from 1980 to 1983. Cases were identified by regularly contacting the coronary care units of 78 hospitals. Controls were selected from men of roughly the same ages who were admitted to the same hospitals with other conditions. Subjects were interviewed in hospital; $13 \%$ of the patients with myocardial infarction and $7 \%$ of the controls refused. 